\title{
Septal transposition: a novel technique for preservation of the nasal septum during endoscopic endonasal resection of olfactory groove meningiomas
}

\author{
Technical note
}

\author{
Marc R. Rosen, M.D., ${ }^{1}$ Mindy R. Rabinowitz, M.D., ${ }^{1}$ Christopher J. Farrell, M.D., ${ }^{2}$ \\ Madeleine R. Schaberg, M.D., M.P.H., ${ }^{3}$ and James J. Evans, M.D.² \\ Departments of ${ }^{1}$ Otolaryngology-Head and Neck Surgery and ${ }^{2}$ Neurological Surgery, Thomas Jefferson \\ University, Philadelphia, Pennsylvania; and ${ }^{3}$ Department of Otolaryngology-Head and Neck Surgery, \\ New York Eye and Ear Infirmary of Mount Sinai, New York, New York
}

\begin{abstract}
Endonasal resection of olfactory groove meningiomas allows for several advantages over transcranial routes, including a direct approach to the bilateral anterior cranial base and dura mater, early tumor devascularization, and avoidance of brain retraction. Although considered minimally invasive, the endoscopic approach to the cribriform plate typically requires resection of the superior nasal septum, resulting in a large superior septal perforation. The septal transposition technique improves preservation of sinonasal anatomy through the elimination of a septal perforation while allowing for wide exposure to the midline anterior cranial base and harvest of a nasal septal flap. Herein, the authors describe a 39-year-old female who presented with a progressively enlarging olfactory groove meningioma. An endoscopic endonasal resection with a septal transposition technique was performed. On follow-up, the nasal cavity had completely normal anatomy with preservation of the turbinates and nasal septum.

The authors conclude that septal transposition is a useful technique that allows wide exposure of the anterior cranial base with maximal preservation of normal nasal anatomy and avoidance of a large septal perforation. (http://thejns.org/doi/abs/10.3171/2014.7.FOCUS14308)
\end{abstract}

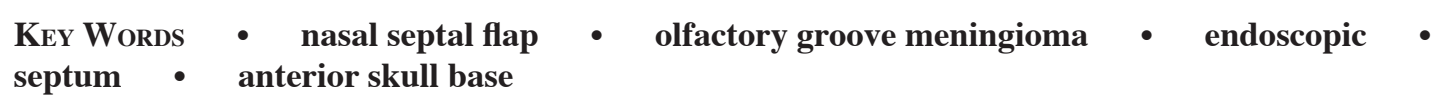

$\mathrm{T}$ THE resection of olfactory groove meningiomas was first described by Cushing in the mid-20th century. ${ }^{2}$ Since that time, a multitude of transcranial approaches have been described to access these midline anterior cranial fossa tumors arising from the cribriform plate. The bifrontal approach provides wide tumor exposure and facilitates cranial base reconstruction; however, it often necessitates bilateral frontal lobe retraction, sacrifice of the anterior sagittal sinus, and cranialization of the frontal sinus. Furthermore, it provides delayed visualization of critical neurovascular structures, including the optic nerves and anterior cerebral arteries. Unilateral approaches, including the subfrontal, supraorbital, and pterional approaches, avoid bilateral retraction and may enable earlier dissection of neurovascular structures but provide a narrower working corridor for tumor resection and less access to the bilateral anterior cranial base. In accord with skull base principles, the transbasal and orbitozygomatic extensions facilitate reduced frontal lobe retraction and postoperative cerebral edema but may lead to increased operative time and cosmetic disfigurement. ${ }^{9,10}$ With the more recent advances in extended en- doscopic endonasal approaches to the cranial base, these techniques have been applied to olfactory groove meningiomas with varied results. ${ }^{5,10}$ Advantages of the extended endoscopic approaches include the absence of brain retraction, early tumor devascularization via coagulation of the anterior and posterior ethmoidal arteries, and the possibility of more complete tumor resection (Simpson Grade I) through improved removal of involved hyperostotic bone along the anterior cranial fossa. ${ }^{8}$ Although these approaches have evolved as a means of minimizing intracranial manipulation, current endoscopic endonasal techniques may result in significant disruption of normal sinonasal anatomy including turbinate and septum resection. ${ }^{3,4}$ In addition to the large septectomy and resultant septal perforation required to access the cribriform plate, standard endonasal access techniques reduce the available size of a contralateral nasoseptal flap should it be needed in the future.

In this report, we describe a novel endoscopic approach to the anterior cranial base that enables septal flap preservation and avoids septal perforation by transposing the septum rather than performing a septectomy. 


\section{Surgical Technique}

The sinonasal cavity is prepared by applying bilateral pledgets with $4 \mathrm{ml}$ of $4 \%$ cocaine. These pledgets are removed after 5 minutes. The nasal cavity is inspected bilaterally using a $0^{\circ}$ endoscope, and the surgeon determines, based on septal deviation and possible spurs, on which side the nasoseptal flap should be raised. We prefer to raise the flap on the side of the spur or deviation, as it is more likely to perforate the flap on this side. It is often feasible to keep the opposing side's mucosa intact, making it an ideal side on which to base the transposition. (In the featured patient the nasoseptal flap was raised on the left side because of a spur on this side of the septum.) The middle and inferior turbinates are fractured laterally for exposure, and the sphenoid os is identified.

The septum and floor of the nose are injected with $1 \%$ lidocaine with epinephrine $(1: 100,000)$. Care is taken to avoid injecting the sphenopalatine artery, as it is the pedicle to the nasoseptal flap. The superior flap incision is made at the level of the sphenoid os and carried superiorly and anteriorly along the septum to the mucocutaneous junction superiorly. The inferior incision is made along the choanae on the face of the sphenoid at the superior junction of the choanae and carried onto the free edge of the septum and onto the nasal floor to the lateral wall beneath the inferior turbinate and then anteriorly to the nasal sill. A vertical anterior incision is made joining the superior and inferior incisions. The flap is raised and placed in the nasopharynx for protection until usage for reconstruction of the anterior cranial base.

Attention is then turned to the right side, and a hemitransfixion incision is made. Through this incision superior and inferior submucoperiosteal tunnels are raised (Fig. 1). The superior tunnel is raised along the nasal roof and is $5-8 \mathrm{~mm}$ in height; it extends posteriorly to the face of the sphenoid. The inferior tunnel is raised along the inferior border of the septum, along the maxillary crest and out to the piriform aperture, and extends posteriorly to the posterior septum.

Attention is returned to the left side, and a vertical incision is made in the caudal septum $1 \mathrm{~cm}$ posterior to the anterior edge of the septal cartilage, allowing access to the tunnels previously raised. The endoscopic scissors are used to incise the cartilage and bone along the superior and inferior tunnels (Fig. 2). The septum is freed from the vomer posteriorly. This allows complete mobilization of the majority of the bony (including the perpendicular plate of the ethmoid and portion of the vomer) and cartilaginous septum but keeps it attached to the entirely preserved septal mucosa on the right side. With the septum mobile but attached to the adherent mucoperichondrium and periosteum, it can be pushed laterally (transposing it into the right nasal cavity temporarily), allowing bilateral access to the cribriform plate and olfactory groove superiorly (Fig. 3).

With the septum pushed into the right nasal cavity, there is full access to the cribriform plate and anterior cranial base. Under visualization with a $30^{\circ}$ endoscope, a drill and an ultrasonic bone aspirator (Sonopet, Stryker US) are used to remove the bony anterior cranial base from the posterior wall of the frontal sinus to the posterior border of the meningioma at the planum sphenoidale. The bony removal is extended bilaterally to the lateral extent of the fovea ethmoidalis (Fig. 4). The ethmoidal artery branches and the dura are cauterized to disrupt blood supply to the tumor and opened using a retractable blade. The tumor is removed using the neurosurgical technique of internal debulking followed by extracapsular microdissection. Gross-total resection of the tumor and the dural origin is thus achieved. The resultant cranial base
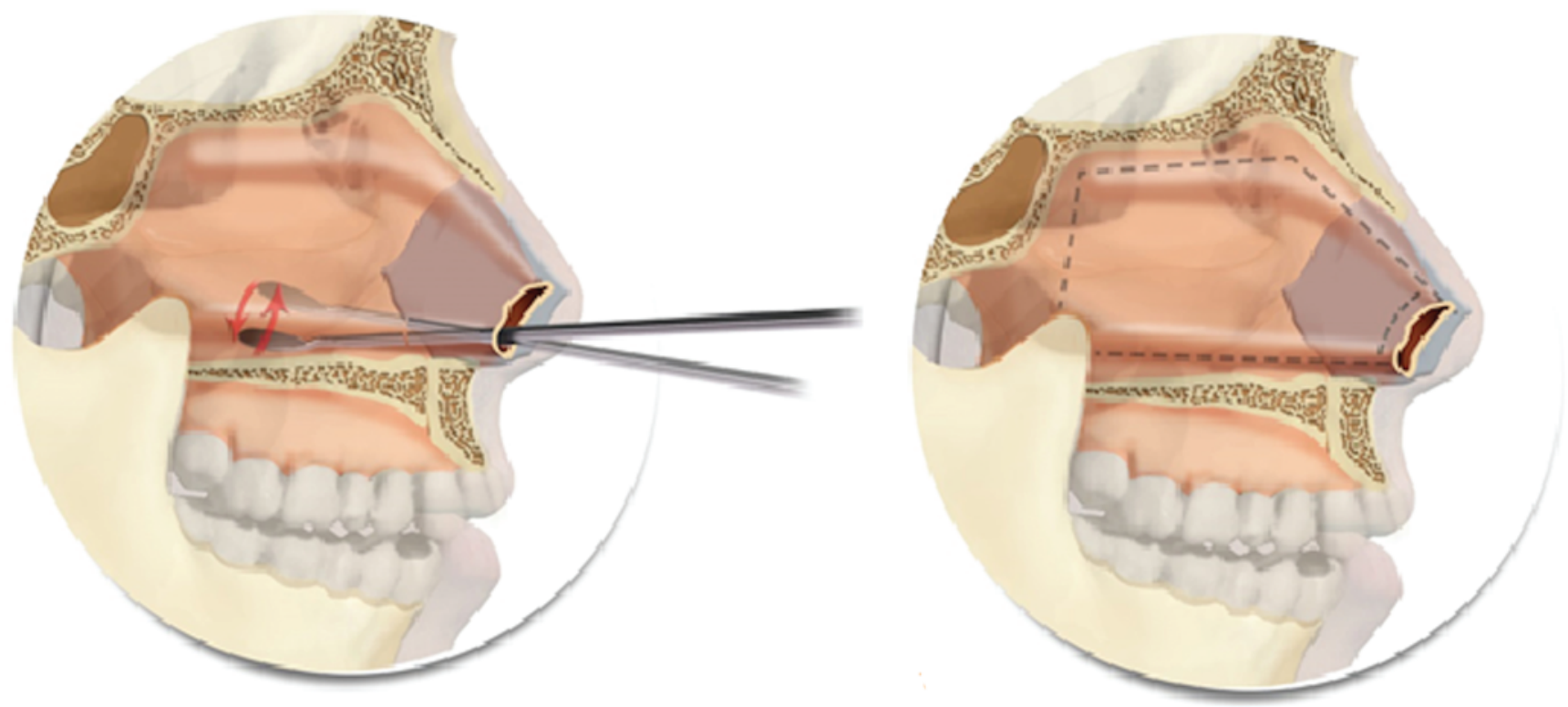

Fig. 1. Septal tunnels. Left: The superior tunnel is raised along the nasal roof and is $5-8 \mathrm{~mm}$ in height; it extends posteriorly to the face of the sphenoid. Right: The inferior tunnel is raised along the inferior border of the septum, along the maxillary crest, and is similarly 5-8 $\mathrm{mm}$ in height and extends posteriorly to the posterior septum. Copyright Marc R. Rosen. Published with permission. 

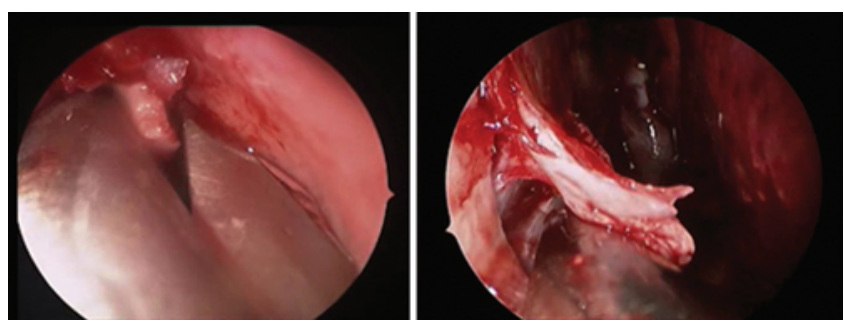

Fig. 2. Endoscopic scissors are used to incise the septal cartilage along the superior (left) and inferior (right) tunnels.

and dural defect is closed using a bilayer button closure of fascia lata, ${ }^{6}$ a nasoseptal flap from the left side, and tissue sealant. The transposed septum is returned to the midline, the hemitransfixion incision is closed, and dissolvable Nasopore packing is placed on the left side to bolster the closure.

\section{Illustrative Case}

A 39-year-old female presented with anosmia and a progressively enlarging olfactory groove meningioma on serial imaging (Fig. 5). An endoscopic endonasal resection of the tumor was performed using a septal transposition technique (Video 1).

VIDEO 1. Endoscopic endonasal resection of a meningioma using the septal transposition technique. See Surgical Technique in the text. Copyright Marc R. Rosen. Published with permission. Click here to view with Media Player. Click here to view with Quicktime.

Gross-total resection of the meningioma and dural origin was achieved, as confirmed on postoperative imaging, and the patient was discharged home on the 4th postoperative day without any complications. Outpatient nasal endoscopy was performed on postoperative Day 10, with the right nasal cavity exhibiting no disruption of the mucosal lining (Fig. 6), and the left side was at the appropriate stage of healing for a harvested nasal septal flap. There was no evidence of a CSF leak, and the nasoseptal flap was tightly adherent to the skull base.

\section{Discussion}

When utilizing the endoscopic endonasal approach to the anterior cranial base for olfactory groove meningiomas, it is possible to maximally preserve the nasal septum in select cases. Current endoscopic approaches require a significant superior septectomy resulting in a large superior septal perforation and associated postoperative morbidity., Septal transposition is a useful technique that allows wide exposure of the anterior cranial base with preservation of the normal nasal anatomy and avoidance of a large septal perforation. This approach is ideal for midline, small cribriform and/or olfactory groove lesions with anosmia preoperatively or in cases in which the loss of olfactory function is expected postoperatively and for tumors that do not involve the septum. Additionally, the approach may be considered for more anterior meningiomas such as those along the crista galli.

The septal transposition approach is not necessary for planum and tuberculum sella meningiomas. It is also not helpful for anterior cranial base meningiomas that have a dural origin extending laterally along the orbital roof
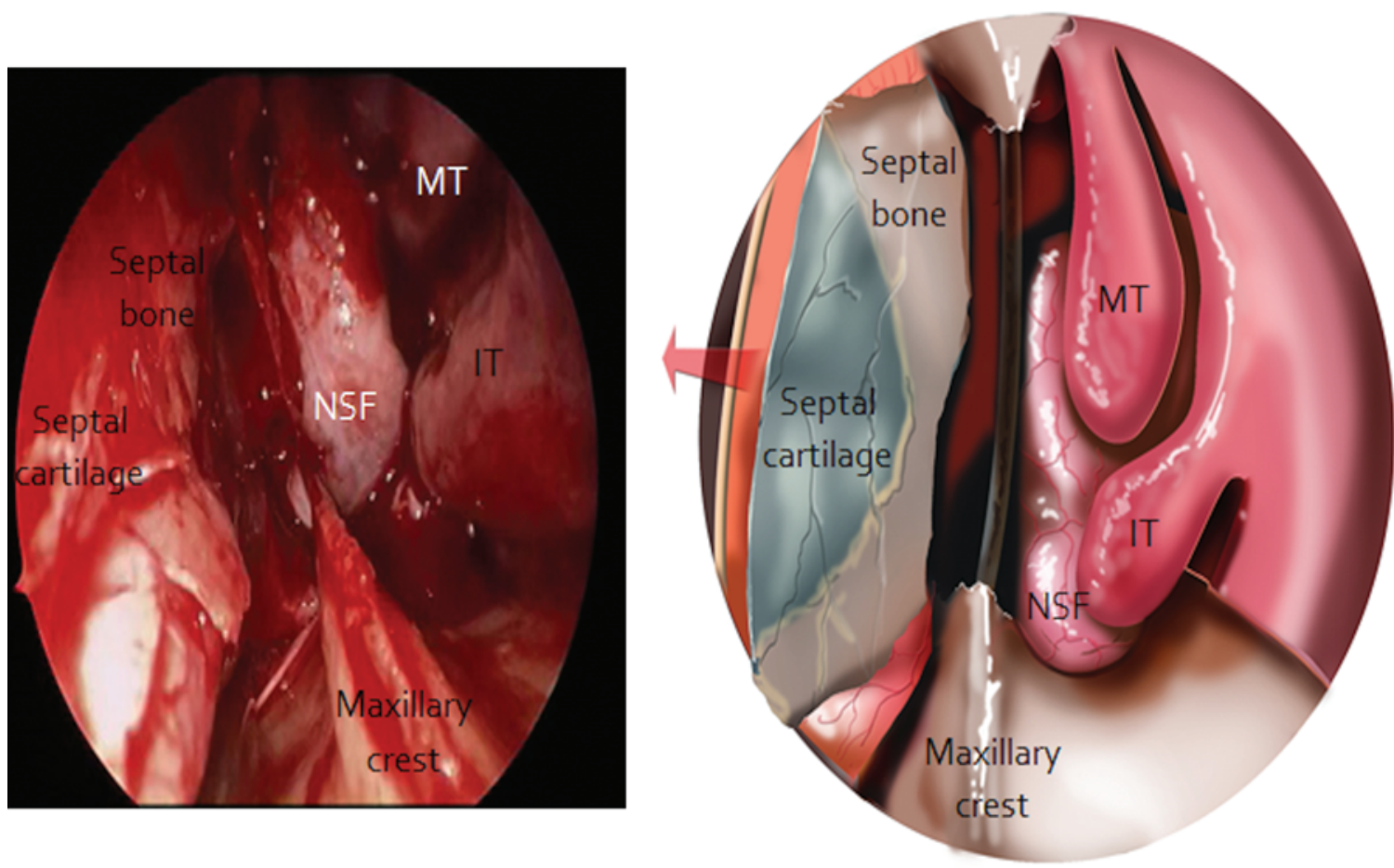

Fig. 3. Transposition of the septum into the right nasal cavity, allowing access to the cribriform plate and olfactory groove superiorly. The maxillary crest appears in the midline. The nasoseptal flap (NSF) lies in the left nasopharynx. Note the left middle turbinate (MT) and left inferior turbinate (IT) and right septal cartilage and bone. Copyright Marc R. Rosen. Published with permission. 


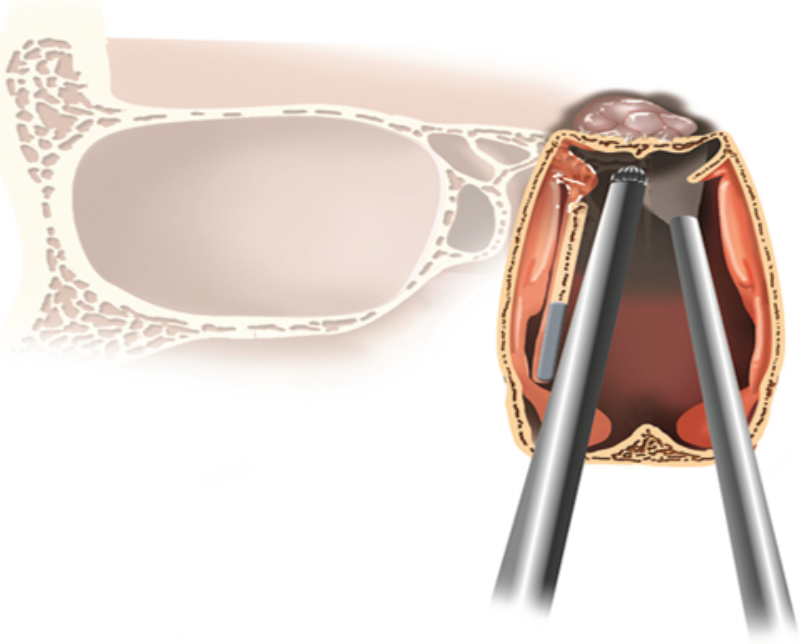

FIG. 4. A drill is used to remove the bony skull base from the posterior wall of the frontal sinus to the posterior border of the meningioma at the planum sphenoidale, and laterally to the lateral extent of the fovea ethmoidalis. Copyright Marc R. Rosen. Published with permission.

beyond the midorbit in the coronal plane. These meningiomas would probably not be entirely resected by an endonasal approach and would probably require a transcranial procedure. Note, however, that the height of the meningioma does not preclude using this technique. Nonetheless, if there is complete encasement of the anterior cerebral arteries without a T2 plane on MRI, one should proceed with great caution, as safe gross-total resection may not be feasible without risk to the vasculature.

Importantly, this approach not only preserves the integrity of the nasal septum, but it also provides at least comparable exposure of the anterior cranial base as would be attained via total septectomy. The entire nasal septum is preserved, resulting in a normal-appearing nasal cavity once the side with the nasal septal flap has healed. Normal nasal function is preserved, and the risk of crusting, infection, and ozena is reduced.

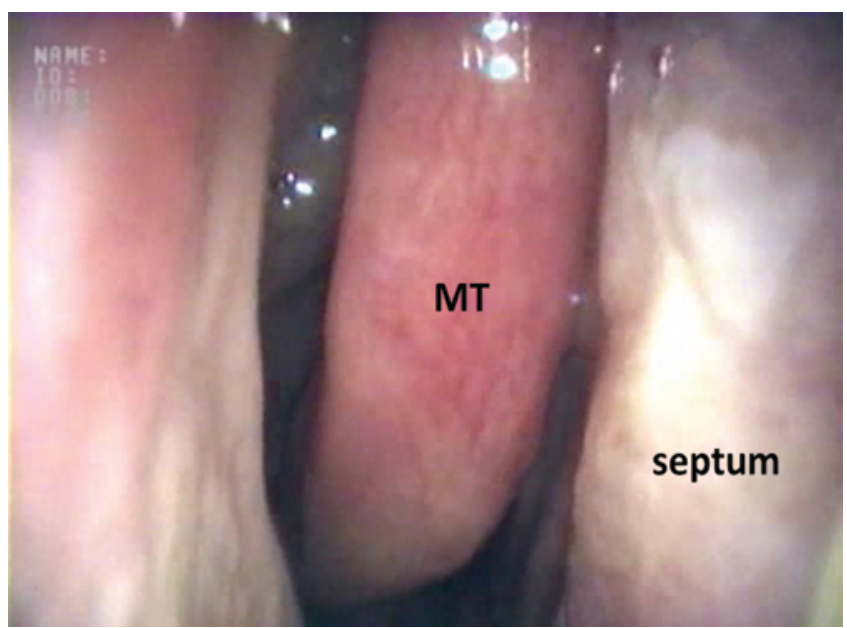

Fig. 6. Nasal endoscopy on postoperative Day 10. The right nasal cavity is shown. The septum and middle turbinate (MT) are noted. Note the smooth mucosal lining without disruption.

\section{Conclusions}

Septal transposition is a useful technique that allows wide exposure of the anterior cranial base with maximal preservation of normal nasal anatomy, the avoidance of a large septal perforation, and a probable reduction in sinonasal morbidity.

\section{Disclosure}

Dr. Evans is a consultant for Stryker and receives royalties from Mizuho. The other authors report no conflict of interest concerning the materials or methods used in this study or the findings specified in this paper.

Author contributions to the study and manuscript preparation include the following. Conception and design: Rosen, Farrell, Schaberg, Evans. Drafting the article: all authors. Critically revising the article: all authors. Reviewed submitted version of manuscript: all authors. Administrative/technical/material support: Rabinowitz, Rosen. Study supervision: Rosen, Evans.
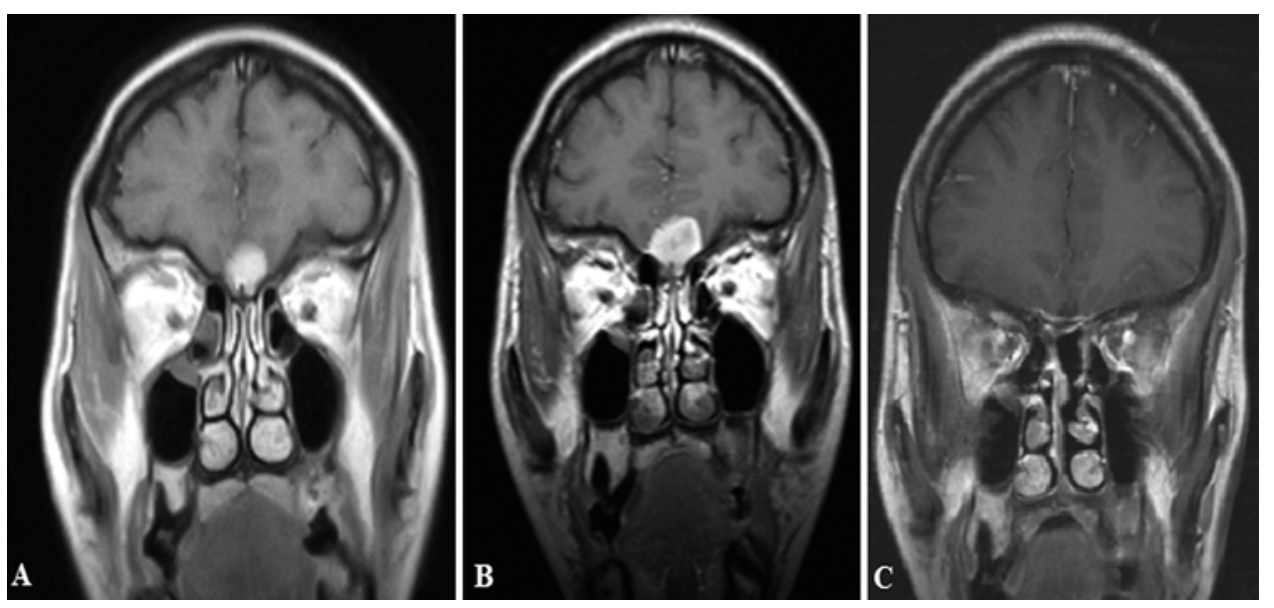

FIG. 5. Preoperative and postoperative imaging. Coronal T2-weighted MR images demonstrating a small extraaxial midline subfrontal mass with uniform enhancement, consistent with a meningioma $16 \mathrm{~mm}$ in its greatest dimension at initial presentation (A) and $23 \mathrm{~mm}$ in its greatest dimension 4 years after presentation (B). Coronal T1-weighted MR image (C) 7 months after surgery. 


\section{Septal transposition}

\section{References}

1. Cavel O, Abergel A, Margalit N, Fliss DM, Gil Z: Quality of life following endoscopic resection of skull base tumors. J Neurol Surg B Skull Base 73:112-116, 2012

2. Cushing H, Eisenhardt L: Meningiomas: Their Classification, Regional Behavior, Life History, and Surgical End Results. Springfield, IL: Charles C Thomas, 1938

3. Gardner PA, Kassam AB, Thomas A, Snyderman CH, Carrau RL, Mintz AH, et al: Endoscopic endonasal resection of anterior cranial base meningiomas. Neurosurgery 63:36-54, 2008

4. Greenfield JP, Anand VK, Kacker A, Seibert MJ, Singh A, Brown SM, et al: Endoscopic endonasal transethmoidal transcribriform transfovea ethmoidalis approach to the anterior cranial fossa and skull base. Neurosurgery 66:883-892, 2010

5. Hadad G, Bassagasteguy L, Carrau RL, Mataza JC, Kassam A, Snyderman $\mathrm{CH}$, et al: A novel reconstructive technique after endoscopic expanded endonasal approaches: vascular pedicle nasoseptal flap. Laryngoscope 116:1882-1886, 2006

6. Luginbuhl AJ, Campbell PG, Evans J, Rosen M: Endoscopic repair of high-flow cranial base defects using a bilayer button. Laryngoscope 120:876-880, 2010

7. Pant H, Bhatki AM, Snyderman CH, Vescan AD, Carrau RL, Gardner P, et al: Quality of life following endonasal skull base surgery. Skull Base 20:35-40, 2010

8. Rachinger W, Grau S, Tonn JC: Different microsurgical approaches to meningiomas of the anterior cranial base. Acta Neurochir (Wien) 152:931-939, 2010
9. Telera S, Carapella CM, Caroli F, Crispo F, Cristalli G, Raus L, et al: Supraorbital keyhole approach for removal of midline anterior cranial fossa meningiomas: a series of 20 consecutive cases. Neurosurg Rev 35:67-83, 2012

10. Van Gompel JJ, Frank G, Pasquini E, Zoli M, Hoover J, Lanzino G: Expanded endonasal endoscopic resection of anterior fossa meningiomas: report of 13 cases and meta-analysis of the literature. Neurosurg Focus 30(5):E15, 2011

Manuscript submitted June 13, 2014.

Accepted July 29, 2014.

Portions of this work were presented in poster form at the North American Skull Base (NASB) Conference held in Las Vegas, Nevada, on February 17-19, 2012.

Please include this information when citing this paper: DOI: 10.3171/2014.7.FOCUS14308.

Supplemental online information:

Video 1: http://mfile.akamai.com/21490/wmv/digitalwbc.down load.akamai.com/21492/wm.digitalsource-na-regional/focus14308_video_1.asx (Media Player).

http://mfile.akamai.com/21488/mov/digitalwbc.download.akamai. com/21492/qt.digitalsource-global/focus14-308_video_1.mov (Quicktime).

Address correspondence to: Mindy R. Rabinowitz, M.D., Thomas Jefferson University, Department of Otolaryngology-Head and Neck Surgery, 925 Chestnut St., 6th Floor, Philadelphia, PA 19107. email: mfigures@gmail.com. 